\title{
Sobre Invenção de Orfeu
}

Mirella Márcia Longo ${ }^{I}$

$\mathrm{D}_{\mathrm{s}}^{\mathrm{t}}$ ECORRIDOS sessenta anos da morte de Jorge de Lima, em 1953, as editoras Jatobá e CosacNaify uniram-se numa justa homenagem ao poeta. Cuidadosamente organizada por Fábio de Souza Andrade, que também assina um esclarecedor posfácio, a edição mais recente de Invenção de Orfeu inclui, além de textos críticos elaborados por Murilo Mendes, João Gaspar Simões e Mário Faustino, uma série de documentos comentados pelo organizador. Entre estes últimos, encontra-se uma carta de Ezra Pound, indicativa de um contato pessoal que se confirma no plano das duas escritas, ambas assinaladas pela presença do canto largo e com ânsia de universalidade.

Conta Murilo Mendes que, encarregado de batizar o livro, hesitou entre Cosmogonia, Canto geral ou Invenção de Orfeu, ficando com o último título: "Pediu-me o poeta que batizasse o livro. Devorado este, hesitei entre Cosmogonia, Canto Geral e Invenção de Orfeu" (p.515). O próprio autor interfere indicando, através de subtítulos, que o texto de Invenção de Orfeu deve ser lido como uma Biografia épica, Biografia total..., Biografia com sondagens. Assim, ao se aproximar do longo poema, o leitor pode buscar um percurso biográfico e associá-lo à trajetória mítica de Orfeu, marcada pela magia da arte, pelo amor, pelo contato com o mundo da morte e pelo regresso a uma vida centrada no canto doloroso da perda. A despeito da descontinuidade, da fragmentação e da superposição de sentidos que predominam na composição, é possível nela de- tectar um fio de natureza biográfica. Segundo João Gaspar Simões, nesse poema da criação, o poeta é, ao mesmo tempo, "o ser que cria e a coisa criada". Em suas palavras: "Muito bem pode ser que Invenção de Orfeu ... seja o poema da criação, nas novas terras do Brasil, da aventura poética em que o criador, o poeta, é, ao mesmo tempo, o ser que cria e a coisa criada" (p.534). Fazendo, de fato, o poema da aventura criativa, Jorge de Lima nos dá notícia de como chegou a ser quem é: o inventor de Orfeu, persona lírica que fala ao longo de dez cantos.

Longe de qualquer linearidade, esboça-se um percurso formativo feito de ciclos que se enovelam em torno de alguns temas e de imagens que se repetem. A subjetividade que se movimenta nos cantos parece mesmo totalizar outros eus. Destroçadas nos caminhos, essas vozes ecoam, agregando-se à voz da última persona e arrastando os seus mantos legados pelas trevas. À medida que se posicionam em relação aos conjuntos temáticos e às imagens obsessivas, os vários eus promovem recorrências, tornando a estrutura bastante complexa.

Principalmente o Canto I dá conta da fundação do espaço que, abrigando o inventado Orfeu, também lhe confere forma. Trata-se do próprio poema, mas igualmente se trata de uma pátria. Ao apresentar a geografia do pantomimo que lhe serve de máscara, Jorge de Lima evoca a história do Brasil, com o seu problemático passado colonial e a sua mitologia romântica. No entanto, à imagem de uma terra procurada e visionada como ilha prodigiosa, superpõe-se 
a noção da poesia, centelha transcendente a ser buscada em um oceano feito de linguagem, força destinada a soprar vida sobre os variados recursos expressivos.

Além do espaço, é focalizada a formação de um mundo interior. À medida que expõe, em tom confessional, um ânimo angustiado e expectante, o poeta apresenta, principalmente entre os Cantos II e VIII, os elementos que ajudam a delinear a intimidade do seu Orfeu, tardio e cristão. Ansiosa por abarcar todos os eus que, no passado, se diluíram, essa intimidade alimenta-se de matéria vertida pela existência, pela fantasia ativa e por vasta herança de símbolos.

Nascido em 1893, na pequena cidade de União dos Palmares, no interior de Alagoas, Jorge de Lima viveu até os sete anos entre a casa grande do engenho da família e o sobradinho da Praça da Matriz. Deslocou-se para Maceió com dez anos; depois foi fazer o curso de medicina que, iniciado na Bahia, seria concluído no Rio de Janeiro, onde residiu desde 1930 até a morte, em 1953. Presentes nas trajetórias de muitos intelectuais da sua geração, essas migrações terminaram por marcar a sua Biografia total.

Invenção de Orfeu mostra os lugares da infância por meio de imagens que evocam desertos bíblicos e, com maior frequência, as paisagens amenas de Virgílio. Minuciosa memória dos sentidos destaca os primeiros contatos da pele, as vivências do terror noturno infantil com o seu corolário de alucinações, as primeiras impressões sexuais. A esses elementos decisivos acrescentam-se a aquisição da linguagem e a tomada de consciência do dom poético, estigma recebido com ambivalência, misto de orgulho e temor. Contudo, a vida vivida não se descola das crenças, dos ritos, dos mitos e da bagagem de leituras. Assim, a descoberta do instinto sexual corresponde à audição das sereias; os ancestrais compõem uma linhagem mítica capaz de gerar o marinheiro que canta dentro dos búzios. Sob o peso da culpa e da dor, o afastamento do mundo tradicional equivale, na emoção, ao parricídio. A lembrança das lavadeiras - presente em outros livros de poemas e também nos romances - associa-se à imagem do pai morto e, simultaneamente, à leitura de Os irmãos Karamazof. A recordação do impacto causado pelo primeiro contato com o episódio de Inês de Castro, em Os lusíadas, é especialmente destacada. Lido sob esse prisma, o Canto IX constitui arqueologia de uma obsessão: a figura da mulher morta e para sempre viva.

Presente em muitos textos escritos por Jorge de Lima, a imagem da mulher amada torna-se, também no último livro, um arco de ligação entre a morte e a vida. Atando a imanência às instâncias sagradas, ela aparece, no poema, como uma glosa à Graça, abrindo, na letra, vasos comunicantes com o espírito que a ultrapassa. Trazendo consigo um mundo imaterial, que a cultura moderna pôs em retração, a amada muitas vezes coincide com o impulso que promove a escrita poética. Associado à aproximação dessa mulher, o instante lírico deve ser visto como manifestação de transcendência, espaço onde se guardam, na perspectiva do poeta, todas as fontes que revitalizam.

Em seu esforço para recompor os fios existenciais, o leitor será levado a perceber que, em algum momento, as paisagens da infância são substituídas por uma terra habitada pelo mal, lugar de queda e danação. Com lentes amplas, o poeta focaliza cenários atingidos por catástrofes, falando do oceano bediondo $e$ 
morto e de um céu consumido em urânio e em abismo. No tecido complexo, não há visão evolutiva. O tempo promove dissolução, de modo que a invenção da persona atual se deve mesmo ao acúmulo das dissoluções anteriores. O poeta exibe múltiplos ciclos de nascimento, paixão, dissolução, todos eivados por anseio de transfiguração. Revendo esse processo - no qual as coisas são desfeitas e, de algum modo, ressurgem marcadas pela morte -, Jorge de Lima também revê os diversos deslocamentos operados em suas opções estéticas.

Ainda que tenham atualidade no contexto do último livro, as referências a uma procura tateante de música podem ser associadas à poesia da primeira fase, quando o poeta manteve-se próximo dos moldes parnasianos. Operando círculos concêntricos nessa poesia final, em cujo âmbito também se torna um objeto de reflexão, a atividade da memória acentuou-se a partir da poesia regionalista afinada à segunda fase do modernismo. De modo similar, o último livro retoma, ainda que revestido com novos matizes, o compromisso com Cristo, afirmado em Tempo e eternidade. Exposto em sua fragilidade de criatura, Cristo exibe, com máxima frequência em Invenção de Orfeu, a feição dos mártires e das vítimas que já mostrara no Livro de sonetos. Composta de um modo que evidencia claramente a força da herança barroca, a figura de Cristo une-se, nesse último livro, à imagem de Orfeu, sugerindo uma face para o homem do século XX. Nos transes experimentados em duas guerras, esse homem teria vivenciado a história como calvário e como inferno.

Centrado no homem que não consegue sossegar, o tecido biográfico destaca a constante sondagem do mundo inte-

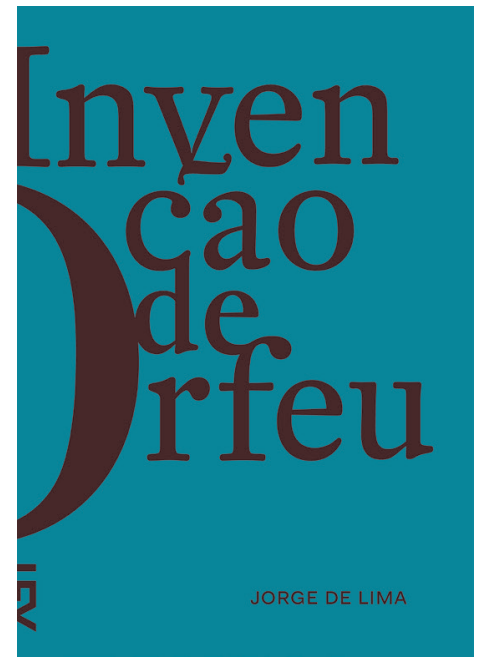

LIMA, J. de. Invenção de Orfeu. Org. e posfácio de Fábio de Souza Andrade. São Paulo: CosacNaify; Jatobá, 2013. 672p.

rior que, intensificada desde Anunciação e encontro de Mira-Celi, atravessou o Livro de sonetos, mantendo-se na obra derradeira. O incessante movimento da imaginação tem sua fonte propulsora personificada, sobretudo, no menino, senhor da criação que palpita adormecido no poema, como semente guardada num fruto que ao futuro se reserva. Principalmente no Canto $X-$ Missão e promissão - entra em dominância o tom profético, discurso apocalíptico que gesta, em si mesmo, um mundo novo.

Mas a Biografia total é também uma Biografia épica. A fim de representar suas rotas existenciais tensamente associadas aos processos de alquimia interna e da própria criação poética, Jorge de Lima evoca, a partir de aproximações e de contrastes, a aventura marítima exaltada por Camões. A essa primeira lembrança ainda se aderem outras, a exemplo das aventuras vividas por Ulisses, por Dante e por Parsifal. 
Em acordo com Lukács, a forma da epopeia constitui objetivação de civilizações coesas, cujos valores coletivos e estáveis concentram-se na figura de um herói. Integrando uma cultura centrada no indivíduo isolado e desprovida de qualquer estabilidade, a subjetividade que fala em Invenção de Orfeu não poderia assumir a posição ocupada pelo herói épico. Jorge de Lima transfere, para o espaço da própria intimidade, o traçado da aventura que, no plano da epopeia, ocupa o espaço exterior. No que tange às escolhas formais, talvez esteja, nessa transferência do externo para o interno, o risco crucial da sua travessia. Ao comentar o paradoxo contido na expressão "epopeia subjetiva”, utilizada por Cavalcanti Proença para qualificar Invenção de Orfen, Alfredo Bosi grifou a "visão febril" do poeta, observando, simultaneamente, o seu discernimento de um "sentido vital, da força misteriosa e inextinguível" que garante a continuidade da vida. Trata-se, segundo Bosi (1978, p.149-57), da Graça. De fato, sobre toda a fragmentação formal e sobre toda a absorção da agonia histórica, afirma-se a confiança em forças capazes de garantir a passagem da morte à criação. É preciso então lembrar que Invenção de Orfeu é também Biografia com sondagens.

Certamente, quem canta, em Invenção de Orfeu, é uma voz fatalmente ferida pelos dilaceramentos da história. Moderna, a sua navegação dá-se a bordo de um barco ébrio e, em seu âmbito, todo ímpeto heroico cede à sensação de fracasso traduzida por cansaço e pelas vertigens da queda. Todavia, no chão onde cai, o poeta encontra, na voz igualmente ferida do seu Cristo, um amparo: "E desabando-me eis que ainda escutei/ aquela voz tão grave e tão divina:/ fui teu céu; e teu chão sempre serei”. Processada ao longo dos diversos cantos que integram o último livro do escritor alagoano, a aventura - no mundo interior e na linguagem - constitui, com inspiração em Dante, uma virtuosa sondagem realizada em torno de forças capazes de transfigurar e criar. Conduzido com rejeição à cultura laica que dá o tom à era moderna, o exercício poético volta-se, sobretudo, para o oceano íntimo, em busca da ilha essencial e inacessível aos poderes dissolventes que, segundo o poeta, governaram o seu tempo e o seu mundo.

\section{Referência}

BOSI, A. Camões e Jorge de Lima. Revista Camoniana, São Paulo, série 2, v.1, p.149-157, 1978.

Mirella Márcia Longo é professora da Universidade Federal da Bahia (UFBA). Pesquisadora do CNPq. Realiza pós-doutorado na Universidade de São Paulo. @ - mimlvl@yahoo.com.br

I Universidade Federal da Bahia, Salvador/BA, Brasil. 